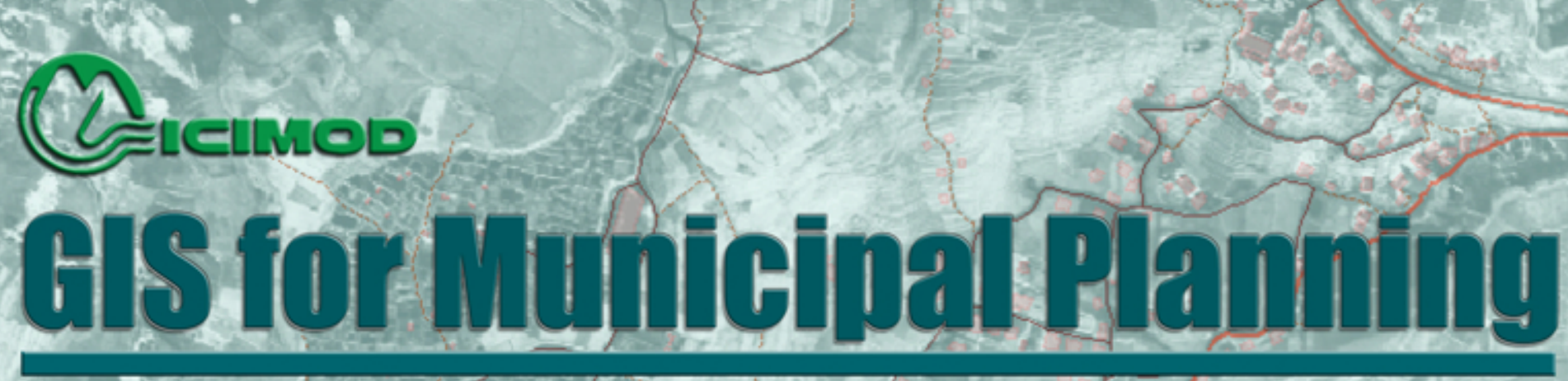

A case study from Karithur murnicipallity

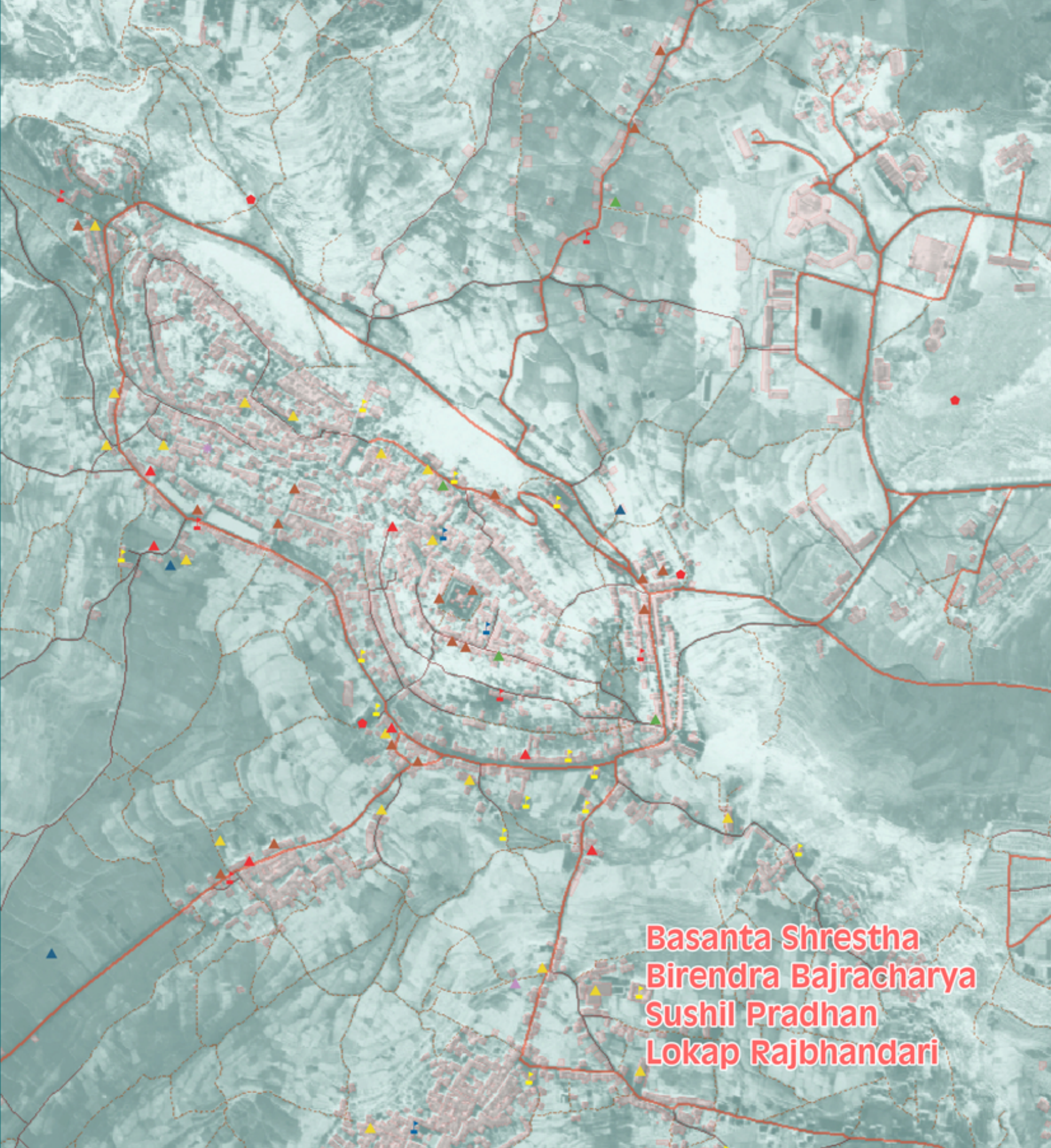




\section{ICIM OD}

\section{about the organisation}

The International C entre for Integrated M ountain Development (IC IM OD) is an independent 'M ountain Learning and Knowledge Centre' serving the eight countries of the Hindu Kush-Himalayas - Afghanistan - , Bangladesh

Bhutan C China , India M yanmar ${ }^{-}$, Nepal $\mathrm{E}$, and Pakistan $\mathrm{C}$ - and the global mountain community. Founded in 1983, IC IM OD is based in Kathmandu, Nepal, and brings together a partnership of regional member countries, partner institutions, and donors with a commitment for development action to secure the future of the Hindu Kush-Himalayas. The primary objective of the Centre is to promote the development of an economically and environmentally sound mountain ecosystem and to improve the living standards of mountain populations. 


\title{
GIS for Municipal Planning
}

A Case Study from Kirtipur Municipality

\author{
Basanta Shrestha \\ Birendra Bajracharya \\ Sushil Pradhan \\ Lokap Rajbhandari
}

International Centre for Integrated Mountain Development (ICIMOD) Mountain Environment and Natural Resources Information Systems (MENRIS) October 2003 
Copyright $\odot 2003$

International C entre for Integrated M ountain Development All rights reserved

\section{Published by}

International C entre for Integrated M ountain Development GPO Box 3226

Kathmandu, Nepal

\section{ISBN 9291157651}

\section{Editorial Team}

J enny Riley (C onsultant Editor)

A. Beatrice Murray (Editor)

Dharma R. Maharjan (Technical Support \& Layout)

Printed and bound in Nepal by

Hill Side Press $(P)$ Ltd.

Kathmandu

The views and interpretations in this paper are those of the contributor(s). They are not attributable to the International Centre for Integrated M ountain Development (IC IM OD) and do not imply the expression of any opinion concerning the legal status of any country, territory, city or area of its authorities, or concerning the delimitation of its frontiers or boundaries. 


\section{Foreword}

ICIMO D has been promoting the use of geographic information systems (GIS) technology in the $\mathrm{H}$ indu Kush-H imalayan $(\mathrm{HKH})$ region for many years through its Mountain Environment and $\mathrm{N}$ atural Resources Information System (MEN RIS) programme. C apacity building and networking activities, combined with applications development, have helped support and promote the wider adoption of GIS for different applications across the region. As a part of this, MEN RIS implemented a project on 'Strengthening of Training C apabilities for GIS A pplications in Integrated Development in the HKH Region' from 1996 to 2000, supported by the Government of the $\mathrm{N}$ etherlands. This project focused on capacity building of national institutions through training programmes in using GIS as a tool in four critical ar eas of mountain development: planning for mountain agriculture and land use management; assessment, planning, and management of natural resources; locational planning for basic infrastructure and services; and slope instability and hazard mapping.

Participants in a series of national and regional training courses on the theme 'Locational planning for basic infrastructure and services' held in Kathmandu used Kirtipur Municipality as a model urban centre and as a part of the training carried out extensive field visits to verify and collect data. The case study on Kirtipur Municipality presented in this publication built upon a post-training exercise by trainees from the course. The study was designed to provide a model demonstrating how GIS can provide a useful tool to support municipal planning processes and decision-making. The datasets developed previously were verified during extensive field visits undertaken in close cooperation with the municipality and supplemented with information obtained from a high-resolution satellite (IKO N O S) image and an orthophoto generated from earlier aerial photographs for the study.

The GIS approach offers major advantages over static mapping. The user can select and overlay different types of data from the datasets greatly facilitating understanding of the existing situation, the planning needs, and the potential impact of planning decisions. Moreover, it is much less resource intensive to update datasets than to prepare new maps so that it helps future planning, and by using a base dataset updated at intervals it is possible to analyse and review trends. The analyses presented in the study indicate clearly how GIS can be used in different urban applications. 0 ne of the most important aspects of the study was being able to develop a comprehensive large-scale database, which is both time and resource consuming. The database that was developed can be used as a foundation for a wide range of applications and will help reduce duplication of effort.

GIS tools can be very useful for municipalities in mountain areas like Kirtipur that are undergoing rapid change without having a proper planning framework. In most parts of $\mathrm{N}$ epal, however, the municipalities do not yet have the resources to start using GIS technology, and in many cases are not aware of how powerful a tool it can be to support and facilitate planning and decision-making at the municipal level. To use GIS technology effectively in a country, the process of database creation and its periodic maintenance must be institutionalised at the local level and adequate technical capability ensured to perform necessary data (spatial) analyses for planning and decision-making.

For the last decade or So, IC IMO D's MEN RIS programme has been working towards enhancing the capacity of partner organisations to use GIS tools, and applying these to ols and 
techniques in various mountain specific applications. There is a continuing demand for these tools by many of our partner institutions and an expressed need for training in their use. This book is a further contribution to these activities, intended both to raise awareness of the potential of GIS in planning applications, and to provide an example that can be used as a base by those interested in applying GIS to their own local situation, particularly municipal level planning. The datasets, associated metadata, maps, and reports used in the study are being prepared as a companion publication on a CD-ROM. The datasets will be integrated with simple GIS functionality so that they can be viewed from a spatial perspective and allow users to investigate the multitude of possibilities for using these tools.

W e hope that this study will do much to demonstrate the potential of GIS as a decision support system tool for integrated municipal planning, both in $\mathrm{N}$ epal and in the $\mathrm{HKH}$ region in general. The book should prove useful to all those interested in applying GIS in urban planning, as well as to those interested in the process of urbanisation and urban planning per se in $\mathrm{N}$ epal.

\author{
Dr. Binayak Bhadra \\ Director of Programmes \\ ICIMOD
}




\section{Executive Summary}

A case study was prepared for Kirtipur Municipality, in Kathmandu D istrict, $\mathrm{N}$ epal, to demonstrate with a practical example the potential for using geo graphic information systems (GIS) as a tool to support municipal planning and decision-making processes, with particular reference to integrated action planning (IAP), a participatory planning approach being implemented in a number of municipalities in $\mathrm{N}$ epal. Kirtipur was selected both because of its proximity to Kathmandu and because it typified the situation in areas with rapid urbanisation, which nevertheless still retain the rural characteristics of an ancient settlement in the midhills of the HKH region. The study started as a post-training exercise by participants in a course on 'Locational planning for basic infrastructure and services' held in Kathmandu, which had used Kirtipur Municipality as a model urban centre. The datasets used in and developed during the course were used as a basis for the case study and verified during extensive field visits undertaken in close cooperation with the municipality. They were supplemented with information obtained from a high-resolution satellite (IKO NOS) image and an orthophoto generated from earlier aerial photographs. These served both to provide basic information and as a way of identifying changes over time.

The background, details of the study, and results are presented. The general information requirements for municipal planning are discussed and a brief overview given of the planning process in $\mathrm{N}$ epal. The design and development of the database, including the data collection approach and data sources, are described in detail. Metadata is provided for standardisation and future use of data. Spatial profiles of the municipality and its wards (the lowest administrative boundary) are presented in the form of thematic maps; with each discussed briefly. Together, these maps provide a clear picture of the existing facilities and their spatial distribution within the municipality. Such maps can be used to help identify priority areas for development or management intervention. Land use and land cover change (derived from aerial photographs taken some years apart) was studied in detail and a first analysis made of the pattern and trend of urbanisation. The land use changes are also presented in map form. The land use criteria used for this first evaluation generated a very good scenario of the trends in growth, which can be used as a basis for developing future development plans. The analysis could be extended in future to include socioeconomic factors.

The advantages of using G IS technologies in municipal planning are discussed, together with the present limitations, which tend to reflect organisational challenges more than technical difficulties. The study underlines the need to develop the capacities of municipalities and institutionalise the process within the local authorities. It is important to provide the motivation for local authorities to generate and maintain spatial information, and use it.

The database generated by the study and the methodology employed will provide the basis for a larger scale database for Kirtipur Municipality. It will be valuable both to Kirtipur Municipality itself and to the many other agencies involved in planning and development activities in the municipality.

Note:

An interactive multi-media CD-Rom is being published separately and will provide access to all the datasets, the associated metadata, maps, and reports used in the study, and will integrate them with simple GIS functionality so that they can be viewed from a spatial perspective. 


\section{Acknowledgements}

W e would like to acknowledge the contributions of the MEN RIS trainees Ms. Sarita Maskey and Mr. Rajendra Man Singh from the Department of Housing and U rban Development (DHUD) and Mr. Tribhuvan Man Singh Pradhan from Kathmandu Metropolitan City who started the study in close cooperation with ICIMOD, and thank them for their untiring efforts in developing and compiling the database during the initial phase. W e also express our sincere appreciation to Kirtipur Municipality for organising a workshop in Kirtipur during the course of the study; and we thank Mr. Anuj Pradhan and Mr. Raju Maharjan from the Municipality in particular for their assistance in the fieldwork and data collection. Special thanks are due to Prof. Barry H aack from G eorge Mason University, W ashington DC, USA, for his review of the draft and useful comments.

W e would like to thank all the individuals and institutions that provided the data and information needed for the study, and all the staff of MEN RIS who have contributed in various ways to its completion. Lastly, we would like to thank our editorial and layout team, Dr. A. Beatrice Murray, Ms. Jenny Riley, and Mr. Dharma R. Maharjan. 


\title{
Acronyms and Abbreviations
}

\author{
CBS Central Bureau of Statistics \\ DEM digital elevation model \\ DHUD Department of Housing and Urban Development \\ DW SS Department of W ater Supply and Sewage \\ GIS geographic information system \\ HKH Hindu Kush-Himalayas \\ HMG/N His Majesty's Government of N epal \\ IAP integrated action plan \\ IC IMO D International C entre for Integrated Mountain D evelopment \\ KMC Kathmandu Metropolitan Corporation \\ KUDP Kathmandu Valley U rban D evelopment Programme \\ MEN RIS Mountain Environment and $\mathrm{N}$ atural Resources Information Systems \\ MPAMKV Master Plan for Agricultural Marketing in the Kathmandu Valley \\ MSIP Multi-Sector Investment Programme \\ NEA N epal Electricity Authority \\ NGO non-government organisation \\ N SET N $\quad$ ational Society for Earthquake Technology \\ NTC N epal Telecommunications Corporation \\ N W SC N epal W ater Supply Corporation \\ PEDP Physical and Environment D evelopment Plan \\ PHECT Public Health Concern Trust \\ TU Tribhuvan University \\ UDLE Urban Development Through Local Effort \\ VDC village development committee
}




\section{Table of Contents}

\section{Foreword}

Acknowledgements

Executive Summary

Acronyms and Abbreviations

Chapter 1 Introduction ................................................................................ 1

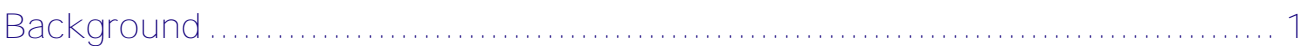

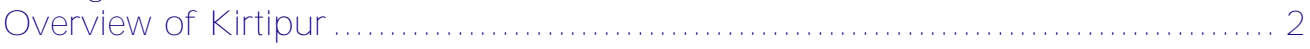

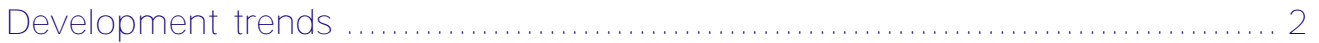

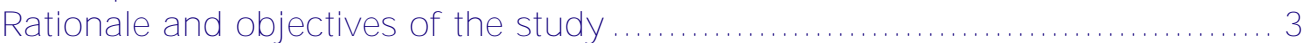

Chapter 2 The Municipal Planning Process in Nepal ......................................... 5

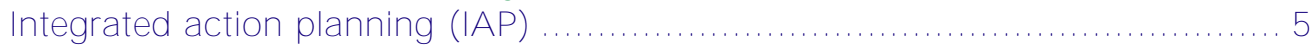

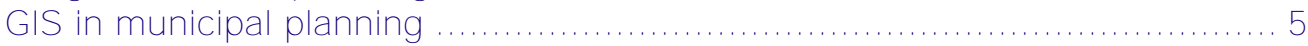

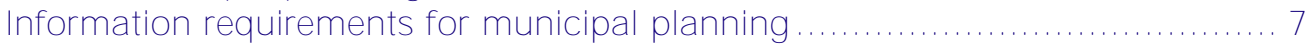

Chapter 3 Design and Development of the Database ..........................................9

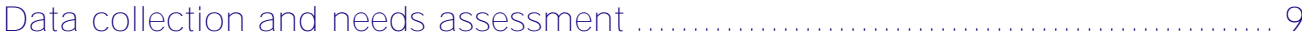

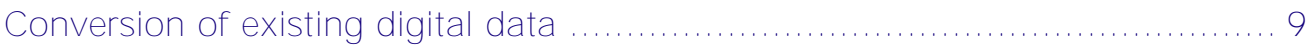

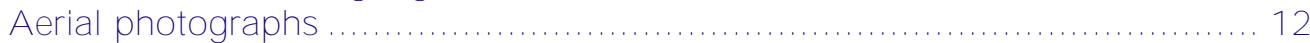

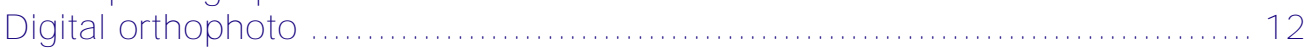

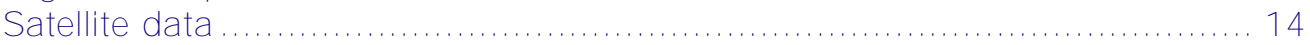

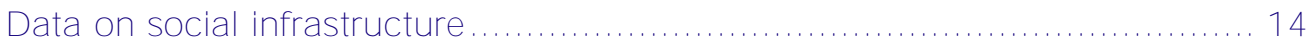

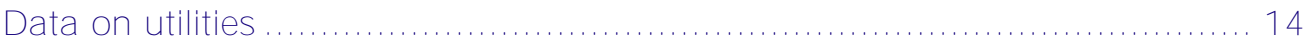

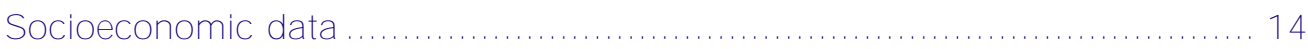

Chapter 4 Spatial Profile of Kirtipur Municipality ........................................... 15

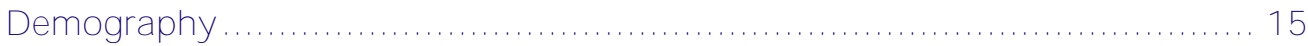

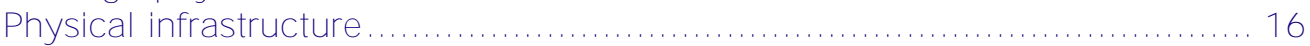

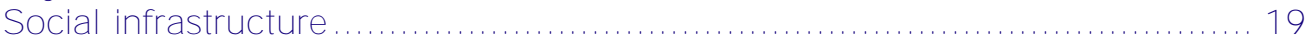

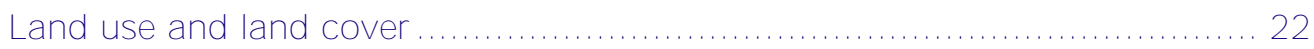

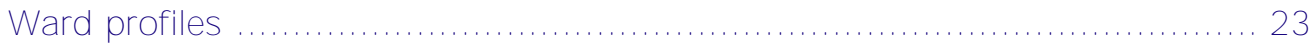

Chapter 5 Change in Land- use and Land Cover .............................................. 25

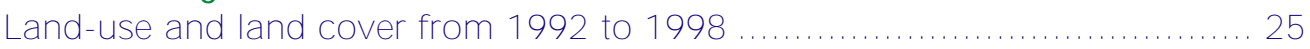

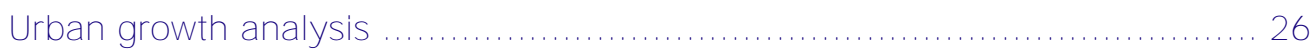

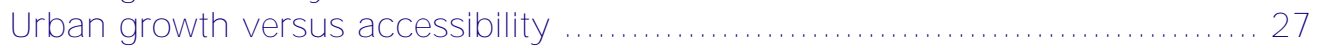

Chapter 6 Conclusions ......................................................................... 29

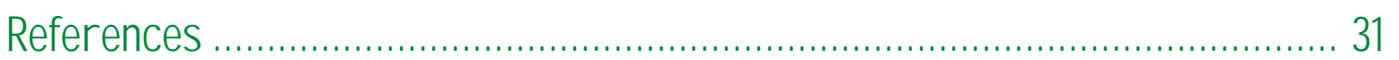

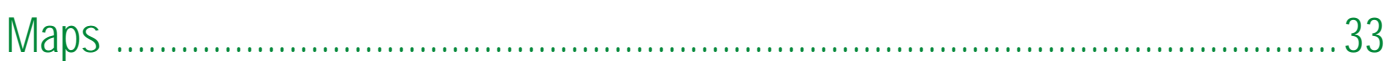

Annex 1 Gener ation of the Or thophoto …..................................................... 75

Annex 2 Impor tant Her itage Sites in Kirtipur Municipality .......................... 77

Annex 3 Metadata ..................................................................................... 79 


\author{
List of maps \\ 1: $\quad$ Orthorectified Aerial Photo for Part of Kirtipur Municipality \\ 2: IKONOS Satellite Image for Part of Kirtipur Municipality \\ 3: Location Map, Kirtipur Municipality, Nepal \\ 4: Administrative Boundaries \\ 5: Population Distribution, 2001 \\ 6: Settlements, 1998 \\ 7: $\quad$ Road Network \\ 8: Industry \\ 9: $\quad$ Electricity Supply and Telephone LIne Network \\ 10: Water Supply \\ 11: Educational Institutions \\ 12: Health and Veterinary Services \\ 13: Public Institutions \\ 14: Shops and Market Areas - all types \\ 15: Food and Vegetable Markets \\ 16: Heritage Sites \\ 17: Land Use and Land Cover Map 1992 \\ 18: Land Use and Land Cover Map 1998 \\ 19: Land Use and Land Cover Change, 1992-1998 \\ 20: Urban Growth, 1992-1998 \\ 21: Land Use Types Conributing to Urban Growth, 1992-1998 \\ 22: Land Use Types Conributing to Urban Growth within 100m of Major Roads \\ (Surfaced and Gravel ), 1992-1998 \\ 23: Possible Areas of Future Urban Expansion \\ 24: Ward Profile - Ward No. 1 \\ 25: Ward Profile - Ward No. 2 \\ 26: Ward Profile - Ward No. 3 \\ 27: Ward Profile - Ward No. 4 \\ 28: Ward Profile - Ward No. 5 \\ 29: Ward Profile - Ward No. 6 \\ 30: Ward Profile - Ward No. 7 \\ 31: Ward Profile - Ward No. 8 \\ 32: Ward Profile - Ward No. 9 \\ 33: Ward Profile - Ward No. 10 \\ 34: Ward Profile - Ward No. 11 \\ 35: Ward Profile - Ward No. 12 \\ 36: Ward Profile - Ward No. 13 \\ 37: Ward Profile - Ward No. 14 \\ 38: Ward Profile - Ward No. 15 \\ 39: Ward Profile - Ward No. 16 \\ 40: Ward Profile - Ward No. 17 \\ 41: Ward Profile - Ward No. 18 \\ 42: Ward Profile - Ward No. 19
}

